\title{
Oncogenic role of HMGA2 in fusion-negative rhabdomyosarcoma cells
}

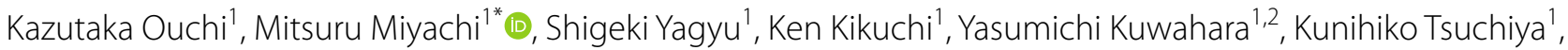 \\ Tomoko lehara ${ }^{1}$ and Hajime Hosoi ${ }^{1}$
}

\begin{abstract}
Background: Rhabdomyosarcoma (RMS) is the most common pediatric soft tissue sarcoma. There are two subtypes, fusion gene-positive RMS (FP-RMS) and fusion gene-negative RMS (FN-RMS), depending on the presence of a fusion gene, either PAX3-FOXO1 or PAX7-FOXO1. These fusion genes are thought to be oncogenic drivers of FP-RMS. By contrast, the underlying mechanism of FN-RMS has not been thoroughly investigated. It has recently been shown that HMGA2 is specifically positive in pathological tissue from FN-RMS, but the role of HMGA2 in FN-RMS remains to be clarified.
\end{abstract}

Methods: In this study, we used FN-RMS cell lines to investigate the function of HMGA2. Gene expression, cell growth, cell cycle, myogenic differentiation, tumor formation in vivo, and cell viability under drug treatment were assessed.

Results: We found that HMGA2 was highly expressed in FN-RMS cells compared with FP-RMS cells and that knockdown of HMGA2 in FN-RMS cells inhibited cell growth and induced G1 phase accumulation in the cell cycle and myogenic differentiation. Additionally, we showed using both gain-of-function and loss-of-function assays that HMGA2 was required for tumor formation in vivo. Consistent with these findings, the HMGA2 inhibitor netropsin inhibited the cell growth of FN-RMS.

Conclusions: Our results suggest that HMGA2 has important role in the oncogenicity of FP-RMS and may be a potential therapeutic target in patients with FN-RMS.

Keywords: HMGA2, Fusion-negative rhabdomyosarcoma, Netropsin

\section{Background}

Rhabdomyosarcoma (RMS) is the most frequent soft tissue sarcoma in children [1]. Two major histological subtypes are described, conventionally named embryonal RMS (ERMS) and alveolar RMS (ARMS), reflecting their morphological similarities to fetal muscle or pulmonary alveoli, respectively [2]. In the era of molecular profiling, two fusion genes have been identified in RMS: the

\footnotetext{
*Correspondence: mmiyachi@koto.kpu-m.ac.jp

${ }^{1}$ Department of Pediatrics, Graduate School of Medical Science, Kyoto Prefectural University of Medicine, 465 Kajii-cho, Hirokoji, Kamigyo-ku, Kyoto 602-8566, Japan

Full list of author information is available at the end of the article
}

PAX3-FOXO1 gene fusion [3] and the PAX7-FOXO1 gene [4]. These gene fusions are found in about $70 \%$ to $80 \%$ of histologically defined ARMS and are not found in ERMS $[5,6]$. Several studies of ARMS have shown that $P A X-F O X O 1$ fusion gene-positive status is associated with worse prognosis than fusion gene-negative status $[7,8]$. Furthermore, patients with fusion gene-negative ARMS have clinical outcomes as favorable as those of ERMS patients compared with fusion gene-positive ARMS, in accordance with the similarity in the molecular features between fusion gene-negative ARMS and ERMS [8]. Hence, identification of this fusion status, regardless of histological subtype, is being incorporated into future

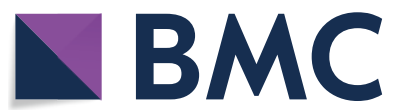

(c) The Author(s) 2020. This article is licensed under a Creative Commons Attribution 4.0 International License, which permits use, sharing, adaptation, distribution and reproduction in any medium or format, as long as you give appropriate credit to the original author(s) and the source, provide a link to the Creative Commons licence, and indicate if changes were made. The images or other third party material in this article are included in the article's Creative Commons licence, unless indicated otherwise in a credit line to the material. If material is not included in the article's Creative Commons licence and your intended use is not permitted by statutory regulation or exceeds the permitted use, you will need to obtain permission directly from the copyright holder. To view a copy of this licence, visit http://creativeco mmons.org/licenses/by/4.0/. The Creative Commons Public Domain Dedication waiver (http://creativecommons.org/publicdomain/ zero/1.0/) applies to the data made available in this article, unless otherwise stated in a credit line to the data. 
Children's Oncology Group (COG) Soft Tissue Sarcoma protocols [9].

Several studies recently revealed that the HMGA2 expression level is significantly higher in fusion genenegative RMS (FN-RMS) than in fusion gene-positive RMS (FP-RMS) and that strong immunohistochemical expression of HMGA2 protein is specific to FN-RMS, suggesting that HMGA2 is a surrogate marker of fusion status in RMS [2, 9]. HMGA2 is a member of the high mobility group A (HMGA) family [10, 11]. The HMGA family protein, which contains three short basic repeats, so-called AT-hooks, binds the minor groove of AT-rich DNA sequences via their DNA-binding domain, which is located in the amino-terminal region of the protein [11]. HMGA protein itself does not have transcriptional activity. It acts as a transcriptional modulator by changing the affinity of transcriptional factors for target DNA sequences and altering chromatin structure, thereby regulating the transcriptional activity of other genes $[12,13]$. However, limited information is available regarding the function of HMGA2 in FN-RMS.

Netropsin is a small-molecule protein that binds to the minor grooves of AT-rich DNA through a sequence- and conformation-dependent mechanism. Because the binding mechanism is similar to that of HMGA family protein, netropsin has been reported to compete with the HMGA family proteins HMGA1 and HMGA2 for DNA binding $[14,15]$.

The aim of this study was to investigate the role of HMGA2 in FN-RMS cells and the antitumor efficacy of netropsin in FN-RMS. We examined the effect of HMGA2 suppression on FN-RMS cells. A reduction in HMGA2 expression led to cell growth inhibition, cell cycle arrest, and myogenic differentiation. Furthermore, we showed that netropsin inhibited the cell growth of FN-RMS cells. These results indicate that HMGA2 represents a new candidate for the treatment of FN-RMS.

\section{Materials and methods Cell culture}

FN-RMS cell lines (RD, RMS-YM, and Rh18), FP-RMS cell lines (Rh30 and RM2), mouse myoblast C2C12 cells, and human embryonic kidney HEK293 cells were cultured in high-glucose Dulbecco's modified Eagle's medium (DMEM) supplemented with 10\% FBS, penicillin $(100 \mathrm{U} / \mathrm{ml})$, and streptomycin $(10 \mathrm{mg} / \mathrm{ml})$ at $37^{\circ} \mathrm{C}$ in a humidified atmosphere containing $5 \% \mathrm{CO}_{2}$. $\mathrm{RD}$, Rh-18, Rh30 and RM2 cell lines were kind gifts from Dr. Peter Houghton (The Research Institute at Nationwide Children's Hospital, Columbus, OH). The RMSYM and HEK293 cell lines were obtained from RIKEN BioResource Center (Tsukuba, Japan). Mouse myoblast C2C12 cells and human embryonic kidney HEK293 were purchased from the American Type Culture Collection (Manassas, VA).

\section{Quantitative reverse transcription-polymerase chain reaction}

Total RNA was extracted from tumor cells using the RNeasy Mini-Kit (Qiagen, Venlo, the Netherlands). cDNA was synthesized using the SuperScript VILO cDNA Synthesis Kit (Invitrogen, Basel, Switzerland). Real-time reverse transcription-polymerase chain reaction (RT-PCR) was carried out on a 7500 Fast Real-Time PCR system (Applied Biosystems, Rotkreuz, Switzerland) with SYBR Premix Ex Taq II (Takara Bio, Shiga, Japan), and relative quantitation was performed using the $2^{-}$ $\Delta \Delta \mathrm{Ct}$ method with glyceraldehyde-3-phosphate dehydrogenase (GAPDH) as the reference gene. The following primer sequences were used: HMGA2, forward primer: 5'-CCTGCTCAGGAGGAAACTGA-3', reverse primer: 5'-CCTCTTCGGC AGACTCTTGT-3'; GAPDH, forward primer: 5'-GCACCGTCAA GGCTGAGAAC-3, reverse primer: 5'-ATGGTGGTGA AGACGCCAGT-3'. Each quantitative RT-PCR experiment was performed in triplicate, and the quantitative RT-PCR experiments were repeated two or three times.

\section{siRNA knockdown of HMGA2}

Transient transfection assays were performed using commercially available siRNAs specific for inhibition of HMGA2 (s15616 and s194863; Life Technologies, Carlsbad, CA, USA) along with a negative control siRNA (4390843; Life Technologies) with Lipofectamine RNAiMAX (Life Technologies) according to the manufacturer's instructions.

\section{Western blotting}

Cells were lysed with Laemmli sample buffer. Protein concentrations in the cell lysates were measured with the Bio-Rad DC Protein Assay (Bio-Rad Laboratories, Hercules, CA, USA). Samples were boiled for $5 \mathrm{~min}$ in sample buffer containing bromophenol blue and $1 \times \beta$-ME, and equal amounts of protein were separated by sodium dodecyl sulfate-polyacrylamide gel electrophoresis (SDS-PAGE). Electrophoretic separation was carried out on $10 \%$ polyacrylamide gel (Bio-Rad Laboratories), and the proteins were subsequently transferred to Immobilon-P membrane (Millipore, Billerica, MA, USA). Membranes were blocked in phosphate-buffered saline (PBS) with Tween 20 (PBST) with 5\% nonfat dry milk powder and incubated with the following primary antibodies: HMGA2 (1:250 dilution; sc-30223, Santa Cruz, Dallas, TX, USA) or FLAG (1:1000 dilution; F3040, Sigma-Aldrich, St. Louis, MO, USA). The primary and secondary antibodies for HMGA2 were diluted with Can 
Get Signal (Toyobo, Osaka, Japan). The membranes were then washed with PBST and incubated with horseradish peroxidase-conjugated goat anti-mouse or anti-rabbit secondary antibody (GE Healthcare, Little Chalfont, UK). Antibody binding was detected with the enhanced chemiluminescence detection system (ECL and ECL Plus; GE Healthcare).

\section{Cell growth analysis}

Cells were plated in normal growth medium in triplicate in 24-well plates. After $24 \mathrm{~h}$, cells were transfected with HMGA2 siRNA or negative control siRNA for an additional $24 \mathrm{~h}$. Then, the cells were lysed under hypotonic conditions, as described previously [16], and nuclei were counted every $48 \mathrm{~h}$ with a Coulter counter (ERMA Inc., Jacksonville, FL, USA) until 96 h later (day 6). All experiments were conducted in triplicate for each cell line.

\section{Cell cycle analysis}

Cells were seeded in normal growth medium in triplicate in 12-well plates. After $24 \mathrm{~h}$, cells were transfected with HMGA2 siRNA or negative control siRNA for an additional $24 \mathrm{~h}$. After transfection, RD, RMS-YM, and Rh18 cells were incubated in normal growth medium for $48 \mathrm{~h}$, $24 \mathrm{~h}$, and $24 \mathrm{~h}$, respectively. Then, cells were harvested and stained with propidium iodide (PI). PI fluorescence was read on a FACSCalibur (BD Biosciences, Franklin Lakes, NJ, USA), and the data were analyzed with Cell Quest software (BD Biosciences). The cell cycle phase was determined on the basis of DNA content using ModFit LT Software (Verity Software House, Topsham, ME, USA) as described previously [17].

\section{Induction of myogenic differentiation}

To induce myogenic differentiation, cells were rinsed thoroughly with PBS $24 \mathrm{~h}$ after siRNA transfection and then cultured with DMEM containing $2 \%$ horse serum (Thermo Fisher Scientific, Waltham, MA, USA), penicillin $(100 \mathrm{U} / \mathrm{ml})$, and streptomycin $(10 \mathrm{mg} / \mathrm{ml})$. Three days later, cells were observed with a BZ-8000 confocal microscope (Keyence, Osaka, Japan) to assess morphological changes. For immunofluorescence, cells on coverslips were fixed with absolute methanol, washed, and incubated with anti-myosin heavy chain (MHC) antibody (M4276, Sigma-Aldrich) for $1 \mathrm{~h}$, rinsed with PBS, incubated with fluorescein isothiocyanate-conjugated antimouse IgG (A-11001, Invitrogen) for $1 \mathrm{~h}$, and visualized using a fluorescence microscope as described previously [18].

\section{Lentiviral procedures and short hairpin RNA}

PLKO.1 lentiviral shRNAmir constructs were obtained from Thermo Fisher Scientific (Waltham, MA, USA;
HMGA2 shRNA, RHS4533; negative control shRNA, RHS 4080). The constructs were co-transfected with the packaging construct (psPAX2) and the VSV-G envelope expression plasmid (pMD2.G), both purchased from Addgene (Cambridge, MA, USA), into 293FT cells using FuGENE 6 (Promega, Madison, WI, USA). For infection, cells were incubated with lentiviral particles and $4 \mu \mathrm{g} /$ $\mathrm{ml}$ polybrene (Nacalai Tesque, Kyoto, Japan), and then selected with puromycin.

\section{Retroviral procedures}

C2C12 cell lines stably expressing Flag-tagged HMGA2 were established using a murine stem cell virus (MSCV) retrovirus expression system (Clontech Laboratories Inc., Madison, WI, USA). Platinum-E cells were transfected in 60 -mm dishes at about $50 \%$ confluence with $1 \mathrm{mg}$ of purified expression vector DNA, $8 \mu \mathrm{l}$ of Enhancer, and $7.5 \mu \mathrm{l}$ of Effectene (Qiagen, Hombrechtikon, Switzerland) in $1 \mathrm{ml}$ of high-glucose DMEM. For retroviral transduction, $\mathrm{C} 2 \mathrm{C} 12$ cells were incubated with retroviral particles and $4 \mu \mathrm{g} / \mathrm{ml}$ polybrene (Nacalai Tesque). Stably transfected cells were selected with $1000 \mathrm{mg} / \mathrm{ml}$ of G418 sulfate (Life Technologies).

\section{In vivo tumorigenesis}

To assess tumorigenesis, $2 \times 10^{6}$ of FN-RMS or C2C12 cells were subcutaneously inoculated into the back of 4-week-old athymic nude mice (BALB/c nu/nu; Shimizu Laboratory Supplies, Kyoto, Japan). Tumor diameter was monitored every 2 or 3 days after the onset of tumor formation. The mice were killed when the tumor size reached $17 \mathrm{~mm}$ in diameter. The mice used for this study were handled in strict adherence with local governmental and institutional animal care regulations. All studies involving mice were performed using protocols approved by the Animal Investigation Committee of Kyoto Prefectural University of Medicine.

\section{Cell viability assay}

WST-8 colorimetric assays were carried out using Cell Count Reagent SF (Nacalai Tesque). RD, RMS-YM, and Rh18 cells were seeded in 96-well plates at $1 \times 10^{4}$ cells/ well, $10 \times 10^{4}$ cells/well, and $8 \times 10^{4}$ cells/well, respectively, in $100 \mu \mathrm{l}$ culture medium per well. After $24 \mathrm{~h}$, the cells were treated for an additional $96 \mathrm{~h}$ with netropsin (Enzo Life Sciences, Farmingdale, NY, USA) dissolved in $\mathrm{H}_{2} \mathrm{O}$. Cell viability was determined colorimetrically by the optical density at a wavelength of $450 \mathrm{~nm}$ using a microplate reader (Multiscan JX; Dainippon Sumitomo Pharmaceutical, Osaka, Japan) as previously described [19]. 


\section{Statistical analysis}

Data are shown as the mean \pm SEM. Single-group data were assessed using the Student's $t$ test. The TukeyKramer test was performed for multiple comparisons. P-values less than 0.05 were considered to represent statistically significant differences.

\section{Results}

\section{Overexpression of HMGA2 in FN-RMS cell lines}

First, we checked the expression of HMGA2 in the FNRMS cell line. As expected, HMGA2 mRNA was highly expressed in FN-RMS cell lines compared with FP-RMS cell lines (Fig. 1).

siRNA knockdown of HMGA2 inhibits FN-RMS cell growth We next examined the biological function of HMGA2 in FN-RMS cells by using the siRNA knockdown approach. The knockdown specifically reduced HMGA2 mRNA and protein expression in RD, RMSYM, and Rh18 RMS cells (Fig. 2a). Knockdown of HMGA2 induced cell growth inhibition in these cells,

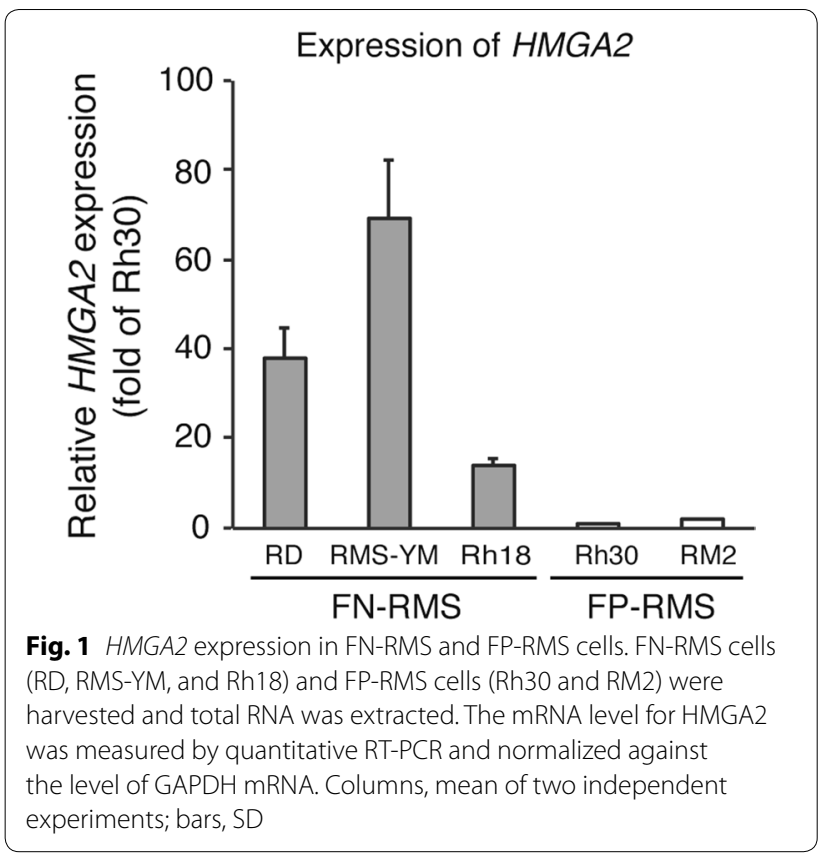

whereas control siRNA did not affect cell growth (Fig. 2b).

\section{siRNA-mediated HMGA2 reduction results in $\mathrm{G} 1$ phase accumulation}

To examine the effect of the HMGA2 reduction on the cell cycle, FACS analysis was performed. As shown in Fig. 2c, HMGA2 siRNA-treated cells exhibited a significantly higher proportion of cells in G1 (siRNA \#1: $58.4 \pm 0.8 \%, 58.6 \pm 4.9 \%$, and $65.5 \pm 2.8 \%$; siRNA \#2: $52.1 \pm 2.6 \%, 54.1 \pm 1.0 \%$, and $61.3 \pm 2.9 \%$, respectively) compared with control cells $(45.2 \pm 0.5 \%, 47.0 \pm 2.0 \%$, and $46.7 \pm 2.3 \%$, respectively) in RD, RMS-YM, and Rh18 cells. The G1 ratio was statistically higher in all cell lines compared with control $(\mathrm{P}<0.01)$. These data suggest that HMGA2 reduction leads to cell cycle arrest in G1.

\section{siRNA knockdown of HMGA2 induces myogenic differentiation of FN-RMS cells}

After siRNA transfection, RD cells were cultured for $72 \mathrm{~h}$ in differentiation medium. HMGA2 reduction morphologically promoted myotube differentiation (Fig. 3a). Cells were then stained with the antibody for the MHC, a marker of myogenic differentiation (Fig. 3b). The MHC positivity rates of HMGA2-reduced cells and control cells were $12.9 \pm 2.6 \%$ and $2.2 \pm 0.8 \%$, respectively $(\mathrm{P}<0.01$; Fig. 3c). These data show that HMGA2 inhibits muscle differentiation.

\section{HMGA2 knockdown inhibits tumor growth of FN-RMS cells in vivo}

To assess the effect of loss of function of HMGA2, we established RMS-YM cell lines in which HMGA2 was stably knocked down using lentiviral vectors encoding HMGA2 shRNA. Western blot experiments confirmed that transduced cells expressed lower levels of HMGA2 protein than non-transduced cells (Fig. 4a). These cells were transplanted subcutaneously into nude mice. Nine weeks after injection, the tumor volume was $80.7 \pm 89.9 \mathrm{~mm}^{3}$ for HMGA2-expressing cells but $396.3 \pm 359.4 \mathrm{~mm}^{3}$ for control cells $(\mathrm{P}=0.12$; Fig. $4 \mathrm{~b})$.

\footnotetext{
(See figure on next page.)

Fig. 2 Effect of HMGA2 siRNA knockdown on FN-RMS cell growth. a RD, RMS-YM, and Rh18 cells were transfected with HMGA2 siRNA or negative control siRNA. Expression of HMGA2 was measured by quantitative RT-PCR and immunoblotting. Columns, mean of three independent experiments; bars, SD. * indicates statistical significance ( $P<0.01$; Student's t-test). $\mathbf{b}$ Cell growth assay. RD, RMS-YM, and Rh1 8 cells were seeded in 24-well plates, cultured for $24 \mathrm{~h}$, and then incubated with HMGA2 siRNA or negative control siRNA (day 0). Cells were harvested every $48 \mathrm{~h}$, and nuclei were counted. Points, mean of three independent experiments; bars, SD. * indicates statistical significance (P<0.01; Student's t-test). c Cell cycle analysis was carried out by using siRNA-treated FN-RMS cells. RD, RMS-YM, and Rh18 cells were harvested and stained with propidium iodide and then analyzed for DNA content with FACSCalibur after siRNA transfection for $48 \mathrm{~h}, 24 \mathrm{~h}$, and $24 \mathrm{~h}$, respectively. Results represent the mean \pm SD of three independent experiments $(P<0.01$; Student's t-test)
} 


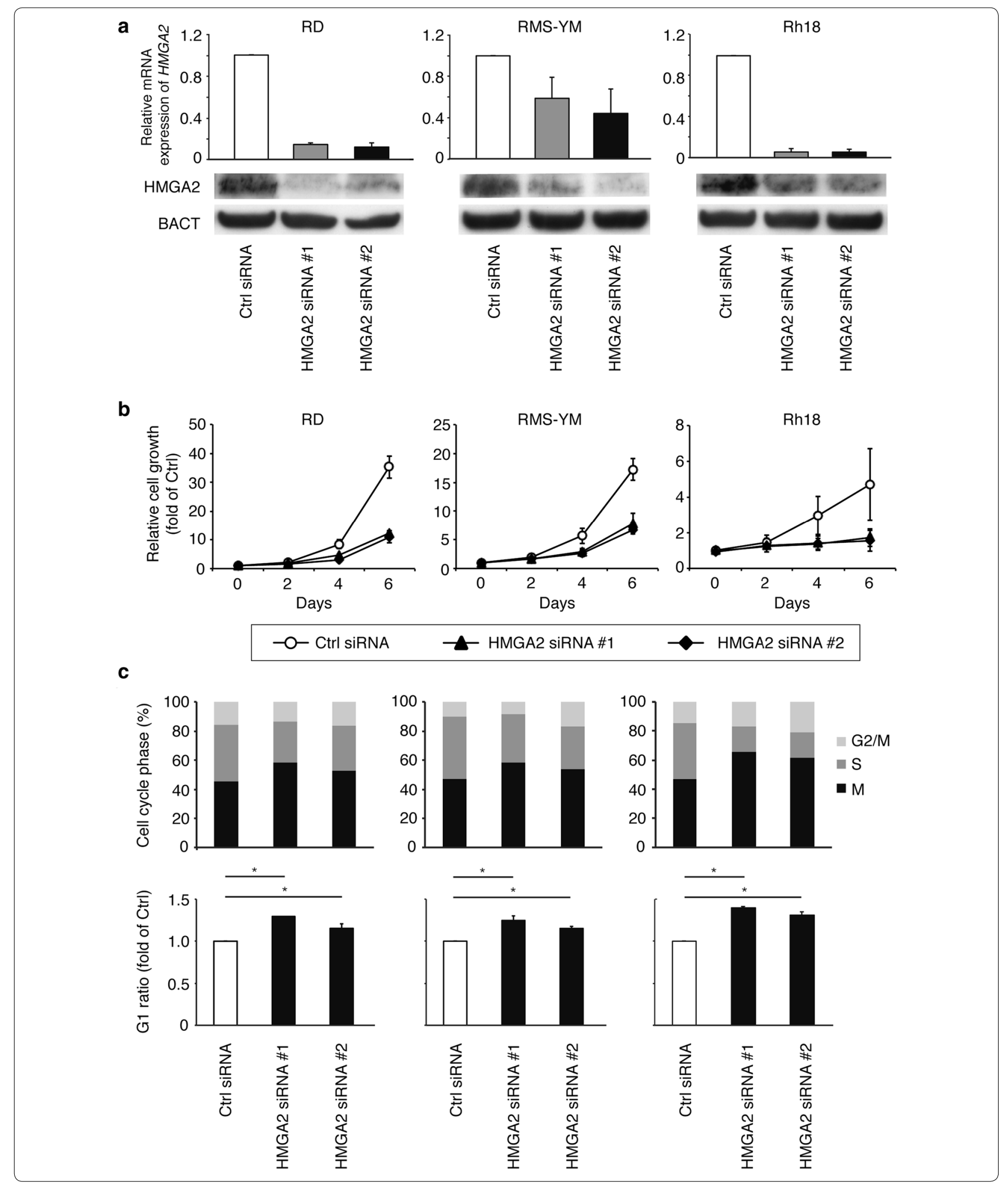

\section{Ectopic HMGA2 expression promotes tumorigenesis} of $\mathrm{C} 2 \mathrm{C} 12$ in vivo

We established Flag-tagged HMGA2-expressing C2C12 cells using MSCV retroviral systems; induction of
Flag-tagged HMGA2 protein expression in the transfected $\mathrm{C} 2 \mathrm{C} 12$ is shown in Fig. 5a. These cells were harvested and transplanted into nude mice to allow tumor formation. Seven weeks after transplantation, the average 


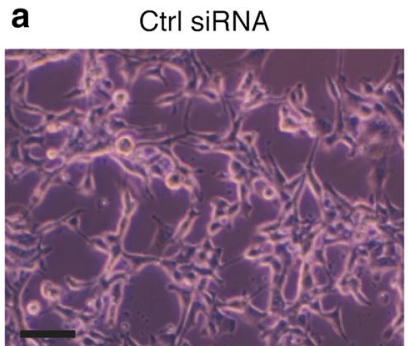

b

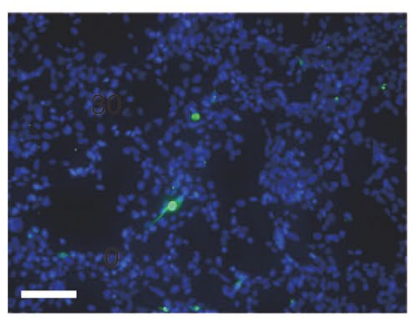

HMGA2 SIRNA \#1

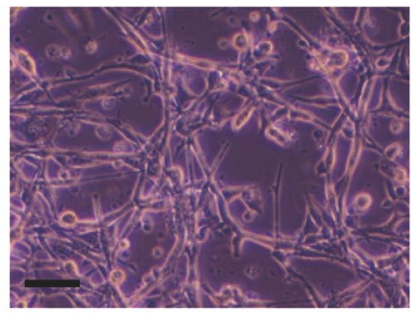

HMGA2 SiRNA \#1

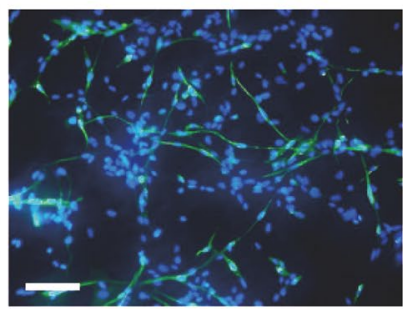

\section{C}

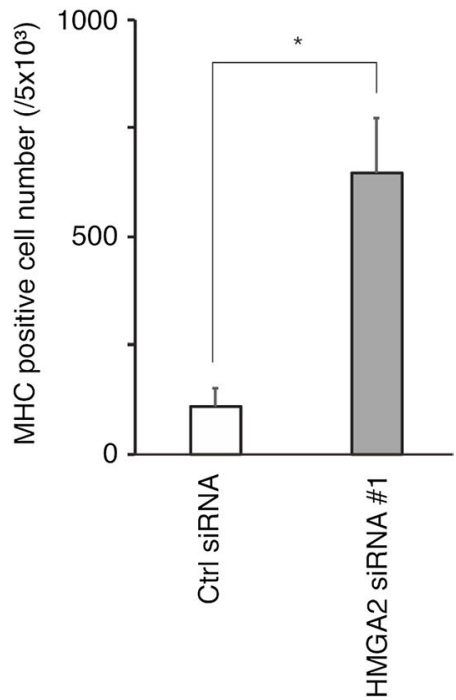

Fig. 3 Derivation of myogenic differentiation by HMGA2 siRNA knockdown. a Representative light microscopy images of HMGA2-depleted RD cells and control RD cells after $72 \mathrm{~h}$ in differentiation medium. Scale bar, $100 \mathrm{~mm}$. Some HMGA2-depleted RD cells formed myotubes. b Fluorescent images of MHC staining after $72 \mathrm{~h}$ in differentiation medium. Scale bar, $50 \mathrm{~mm}$. Representative images of HMGA2-depleted RD cells showing MHC and DAPI (for nuclei), whereas control RD cells showed few MHC-positive cells. c Numbers of MHC-positive cells per $5.0 \times 10^{3}$ cells. Results represent the mean \pm SD of three independent experiments. ${ }^{*} P<0.01$ compared with control RD cells

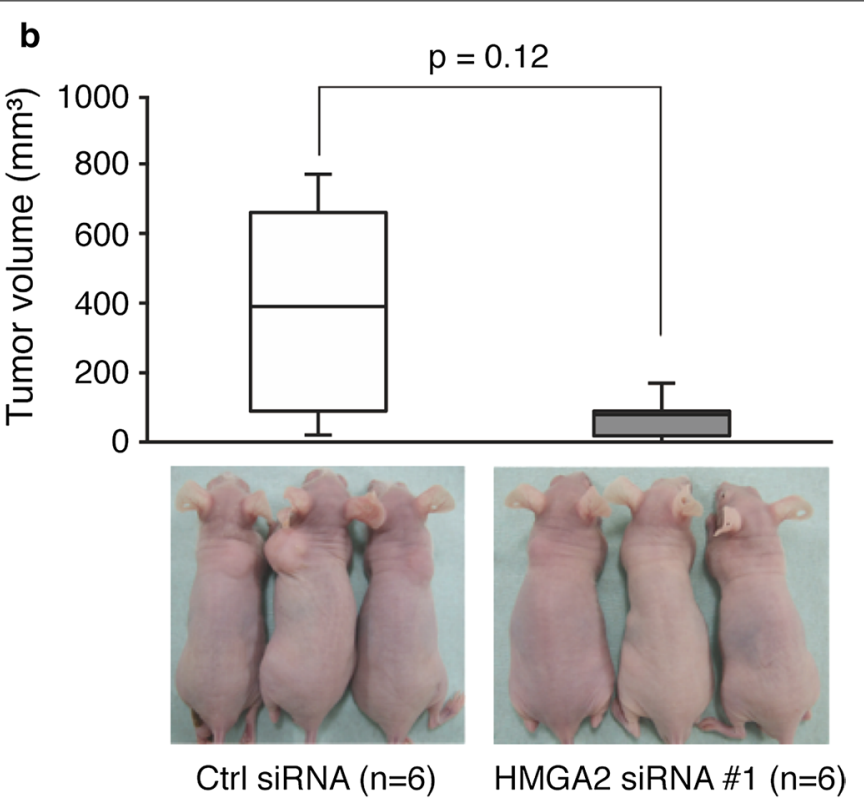

Fig. 4 Effects of HMGA2 knockdown on tumor growth in a murine xenograft model. a Expression of HMGA2 as measured by immunoblotting. $\mathbf{b}$ The upper figure shows the tumor volume 9 weeks after injection of RMS-YM cells into the back of nude mice $(n=6)$. Data are shown by a box plot. The lower images are representative photos of mice

tumor volume was $970.2 \pm 476.9 \mathrm{~mm}^{3}$ for HMGA2-overexpressing $\mathrm{C} 2 \mathrm{C} 12$ cells but $27.2 \pm 28.4 \mathrm{~mm}^{3}$ for control C2C12 cells $(\mathrm{P}<0.01$; Fig. 5b).

\section{Netropsin inhibits growth of FN-RMS cells}

Given that HMGA2 depletion resulted in cell growth (Fig. 2b), we hypothesized that netropsin could inhibit FN-RMS cells by competing with the HMGA2-DNA 

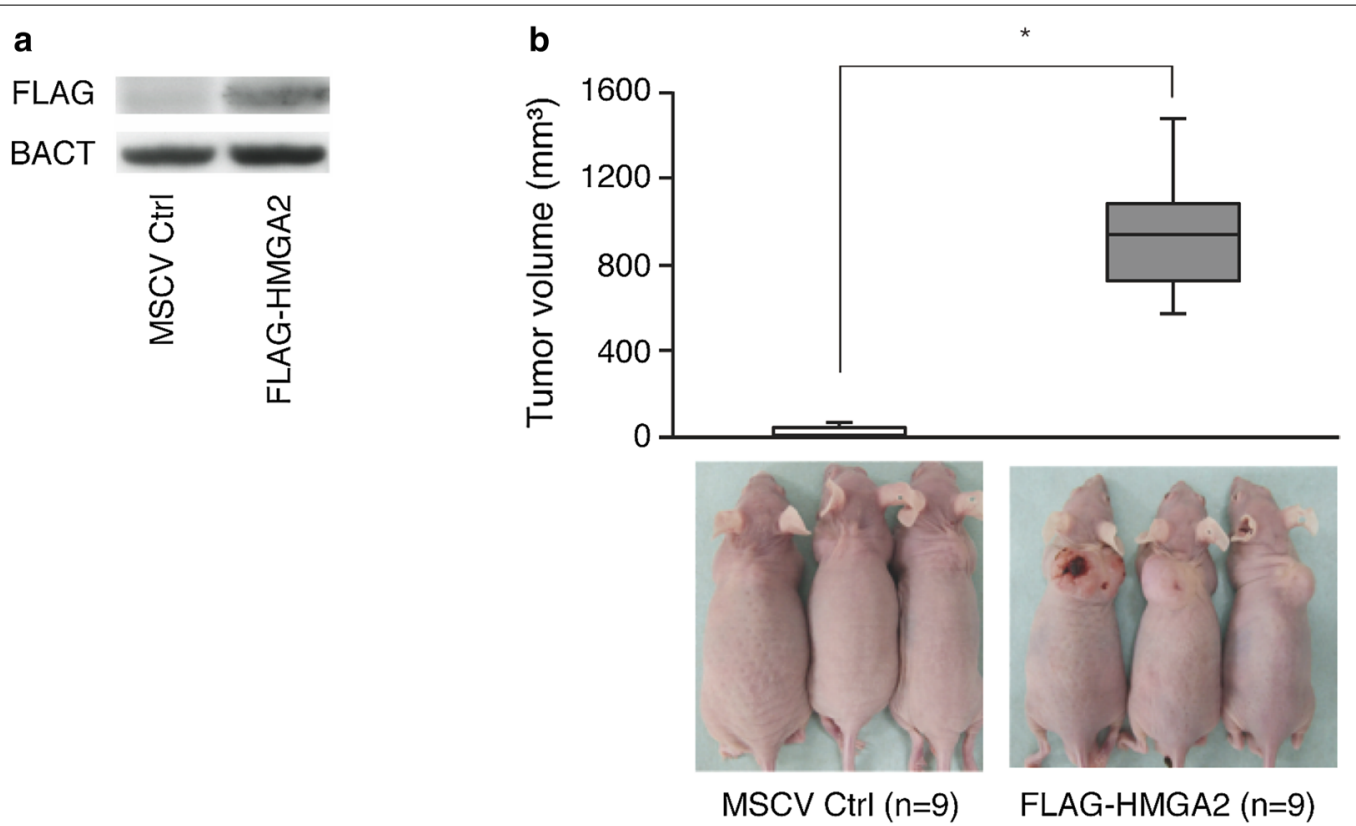

Fig. 5 Effects of HMGA2 on the proliferation of $\mathrm{C} 2 \mathrm{C} 12$ cells in a murine xenograft model. a Expression of FLAG as measured by immunoblotting. b The upper figure shows the tumor volume 7 weeks after injection of $\mathrm{C} 2 \mathrm{C} 12$ into the back of nude mice $(n=9)$. Data are shown by a box plot. *P $<0.01$ compared with control C2C12 cells. The lower images are representative photos of mice

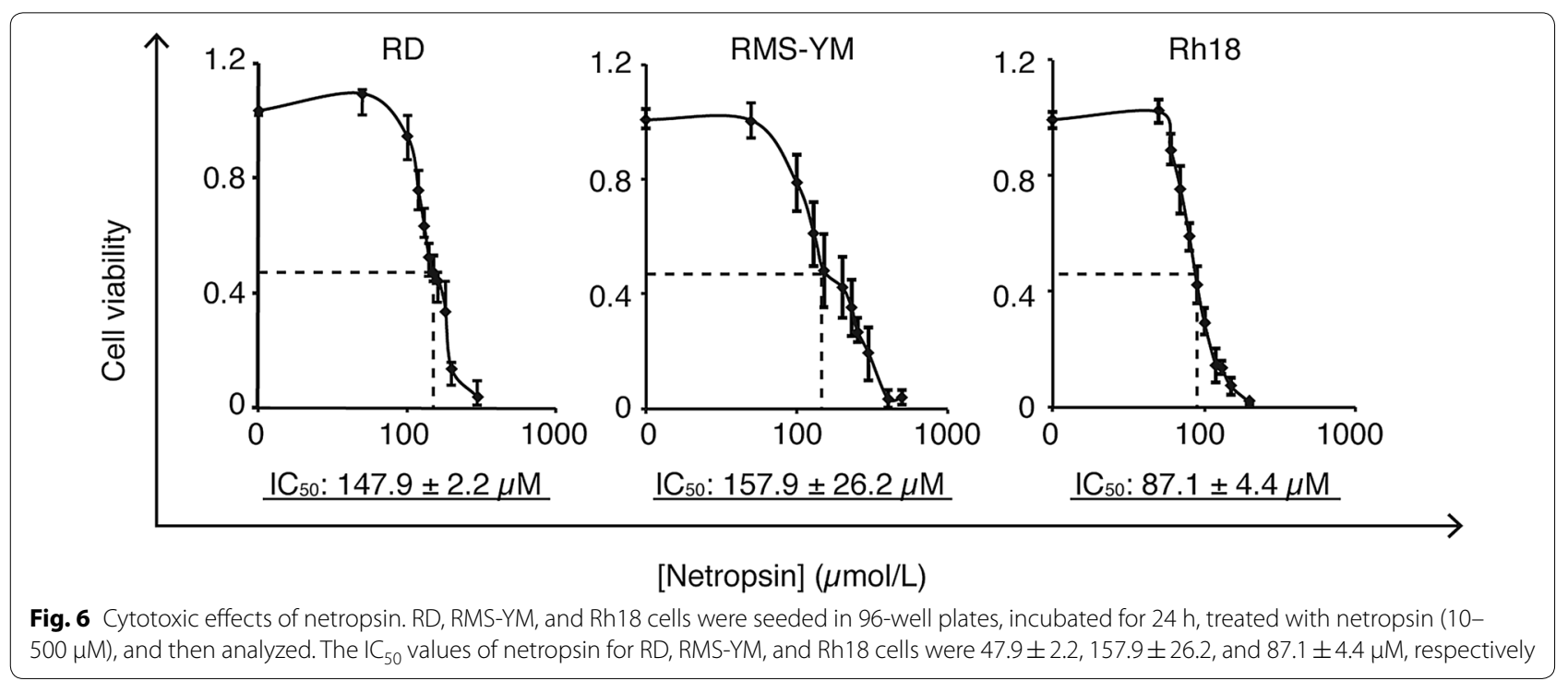

minor groove interaction [14]. When FN-RMS cells were treated with netropsin at concentrations of $10-500 \mu \mathrm{M}$, the proliferation was inhibited in a dose-dependent manner. In this assay system, the $\mathrm{IC}_{50}$ values were $147.9 \pm 2.2$, $157.9 \pm 26.2$, and $87.1 \pm 4.4 \mu \mathrm{M}$ in RD, RMS-YM, and Rh18 cells, respectively (Fig. 6).

\section{Discussion}

The purpose of this study was to investigate the oncogenic role of HMGA2 in FN-RMS cells and the antitumor effect of netropsin on FN-RMS. Indeed, not only did HMGA2 suppression repress tumor genesis, but ectopic HMGA2 expression promoted tumorigenesis in our in vivo model. Administration of netropsin inhibited tumor cell growth. 
Various insights have been provided into FP-RMS [20] and PAX3-FOXO1 is thought to be responsible for their malignant phenotypes [21]. In contrast, the underlying oncogenic factor of FN-RMS has not been fully elucidated [22]. Given that HMGA2 is highly expressed specifically in FN-RMS [2], we investigated whether HMGA2 plays an oncogenic role in FN-RMS. HMGA2 is widely expressed during embryogenesis [23, 24] but is not observed in adult human tissues [24]. Low expression of HMGA2 has been reported in only undifferentiated cells, such as human CD34-positive hematopoietic stem cells [25], mouse preadipocyte cells [26], or meiotic and postmeiotic cells [27, 28]. A high expression of HMGA2 has been observed in pancreatic carcinomas [29], non-small cell lung carcinomas [30], and squamous carcinomas of the oral cavity [31]. Moreover, HMGA2 expression is associated with a more malignant phenotype and a poor prognosis in squamous carcinomas of the oral cavity [31], nasopharyngeal carcinomas [32], glioblastoma [33], esophageal squamous carcinoma [34], lung cancer [35], and atypical teratoid/rhabdoid tumor [36]. We demonstrated that $H M G A 2$ reduction inhibited FN-RMS tumor growth in vivo (Fig. 4) and that ectopic HMGA2 expression resulted in tumor development in vivo (Fig. 5). These results show the oncogenic role of HMGA2 in FN-RMS. The reason for the high HMGA2 expression in FN-RMS remains unclear. One possible mechanism is a genomic gain or amplification. Indeed, a genomic gain or amplification was observed in the region of chromosome 12q13-15, which is the locus of HMGA2, in FN-RMS [37, 38]. Another possible mechanism is a position effect due to a chromosomal rearrangement. Storiazzi et al. investigated a case of polycythemia vera with $H M G A 2$ gene rearrangement and found that the upregulation of the $H M G A 2$ transcript was very likely due to a position effect [39].

As the underlying mechanism of the oncogenesis, the effects of HMGA2 on cellular proliferation, invasion, the epithelial-mesenchymal transition, and apoptosis inhibition have been reported in various tumor cells [34, 40-45]. Cai et al. [42] showed that dysregulated HMGA2 contributed to cellular proliferation through cell cycle progression in prostate cancer. Our study showed that downregulation of HMGA2 led to cell cycle arrest and inhibited cell proliferation in FN-RMS (Fig. 2b, c). These results indicate that high HMGA2 expression causes cell cycle upregulation and cell growth. Moreover, in our study, the HMGA2 reduction induced myogenic differentiation of FN-RMS cells (Fig. 3). In the skeletal muscle lineage, HMGA2 expression is high in proliferating skeletal myoblasts and is significantly reduced with muscle differentiation [46].
RMS displays a myogenic phenotype with the expression of MyoD and desmin [47] but fails to complete terminal differentiation $[48,49]$. These data indicate that oncogenesis of FN-RMS may result from not only cell growth, but also differentiation failure caused by the dysregulated function of HMGA2.

Along these lines, we examined whether netropsin might have an antitumor effect in FN-RMS. Indeed, netropsin inhibited the proliferation of FN-RMS in a dose-dependent manner (Fig. 6). Netropsin is a minor groove-binding protein targeting AT-rich DNA. Such a minor groove of AT-rich DNA sequences is also a binding site for HMGA family proteins. Therefore, netropsin competes with the HMGA family proteins HMGA1 and HMGA2 for DNA binding and interferes with their function [14, 15]. Lau et al. [50] showed that netropsin inhibited HMGA1-expressing medulloblastoma cell growth in vitro and in vivo, with a reduction in HMGA1-targeted RNA promoter activity and expression. The $\mathrm{IC}_{50}$ value of netropsin in that study was in the micromolar order, as in our findings. These results make this minor grove inhibitor a promising antitumor agent for HMGA2-expressing FN-RMS. The limitation of this finding is that it is not clear whether the antitumor effect of netropsin on FN-RMS cells is due to specific inhibition of HMGA2. Investigation of HMGA2-target gene expression could prove its specificity. However, the HMGA2 target gene contributing to the proliferation of FN-RMS cells is still unknown.

\section{Conclusions}

In conclusion, this study has yielded two important observations. First, high HMGA2 expression leads to FN-RMS oncogenesis and represents a potentially attractive therapeutic target in FN-RMS. Second, netropsin, a small-molecule minor groove-binding protein, is a promising agent for the treatment of FN-RMS patients.

\section{Abbreviations \\ RMS: Rhabdomyosarcoma; ERMS: Embryonal rhabdomyosarcoma; ARMS: Alveolar rhabdomyosarcoma; COG: Children's Oncology Group; FN-RMS: Fusion gene-negative rhabdomyosarcoma; FP-RMS: Fusion gene-positive rhabdomyosarcoma; HMGA: High mobility group A; RT-PCR: Reverse transcription-polymerase chain reaction; GAPDH: Glyceraldehyde-3-phos- phate dehydrogenase; SDS-PAGE: Sodium dodecyl sulfate-polyacrylamide gel electrophoresis; PBS: Phosphate-buffered saline; PBST: Phosphate-buffered saline with Tween 20; PI: Propidium iodide; MHC: Myosin heavy chain; MSCV: Murine stem cell virus.}

\section{Acknowledgements}

We would like to thank ThinkSCIENCE (http://www.thinkscience.co.jp) for English language editing. 


\section{Authors' contributions}

$\mathrm{KO}$ performed experiments and analysis and prepared the manuscript. MM, $\mathrm{SY}, \mathrm{KK}, \mathrm{YK}, \mathrm{KT}, \mathrm{Tl}$, and $\mathrm{HH}$ conceived and designed the experiments. All authors read and approved the final manuscript.

\section{Funding}

This work was supported by the grant received from Japan Society for the Promotion of Science (\#26860819 and \#25253095). The funders had no role in study design, data collection, analysis, and interpretation; presentation of the manuscript; and decision to submit the manuscript for publication.

\section{Availability of data and materials}

The datasets used and analyzed during the current study are available from the corresponding author on reasonable request.

\section{Ethics approval and consent to participate}

The mice used for this study were handled in strict adherence with local governmental and institutional animal care regulations. All studies involving mice were performed using protocols approved by the Animal Investigation Committee of Kyoto Prefectural University of Medicine.

\section{Consent for publication}

Not applicable.

\section{Competing interests}

There is no conflict of interest to disclose.

\section{Author details}

${ }^{1}$ Department of Pediatrics, Graduate School of Medical Science, Kyoto Prefectural University of Medicine, 465 Kajii-cho, Hirokoji, Kamigyo-ku, Kyoto 602-8566, Japan. ${ }^{2}$ Department of Molecular Biochemistry, Graduate School of Medical Science, Kyoto Prefectural University of Medicine, 465 Kaji-cho, Hirokoji, Kamigyo-ku, Kyoto 602-8566, Japan.

Received: 22 August 2019 Accepted: 19 May 2020 Published online: 24 May 2020

\section{References}

1. Gurney JG, Severson RK, Davis S, Robison LL. Incidence of cancer in children in the United States Sex-, race-, and 1-year age-specific rates by histologic type. Cancer. 1995;75(8):2186-95.

2. Davicioni E, Anderson MJ, Finckenstein FG, Lynch JC, Qualman SJ, Shimada $\mathrm{H}$, et al. Molecular classification of rhabdomyosarcoma-genotypic and phenotypic determinants of diagnosis: a report from the Children's Oncology Group. Am J Pathol. 2009;174(2):550-64.

3. Galili N, Davis RJ, Fredericks WJ, Mukhopadhyay S, Rauscher FJ 3rd, Emanuel BS, et al. Fusion of a fork head domain gene to PAX3 in the solid tumour alveolar rhabdomyosarcoma. Nat Genet. 1993;5(3):230-5.

4. Davis RJ, D'Cruz CM, Lovell MA, Biegel JA, Barr FG. Fusion of PAX7 to FKHR by the variant $\mathrm{t}(1 ; 13)(\mathrm{p} 36 ; \mathrm{q} 14)$ translocation in alveolar rhabdomyosarcoma. Cancer Res. 1994;54(11):2869-72.

5. Anderson J, Gordon T, McManus A, Mapp T, Gould S, Kelsey A, et al. Detection of the PAX3-FKHR fusion gene in paediatric rhabdomyosarcoma: a reproducible predictor of outcome? Br J Cancer. 2001:85(6):831-5.

6. Barr FG. Gene fusions involving PAX and FOX family members in alveolar rhabdomyosarcoma. Oncogene. 2001:20(40):5736-46.

7. Skapek SX, Anderson J, Barr FG, Bridge JA, Gastier-Foster JM, Parham DM, et al. PAX-FOXO1 fusion status drives unfavorable outcome for children with rhabdomyosarcoma: a children's oncology group report. Pediatr Blood Cancer. 2013;60(9):1411-7.

8. Williamson D, Missiaglia E, de Reynies A, Pierron G, Thuille B, Palenzuela G, et al. Fusion gene-negative alveolar rhabdomyosarcoma is clinically and molecularly indistinguishable from embryonal rhabdomyosarcoma. J Clin Oncol. 2010;28(13):2151-8.

9. Rudzinski ER, Anderson JR, Lyden ER, Bridge JA, Barr FG, Gastier-Foster $\mathrm{JM}$, et al. Myogenin, AP2beta, NOS-1, and HMGA2 are surrogate markers of fusion status in rhabdomyosarcoma: a report from the soft tissue sarcoma committee of the children's oncology group. Am J Surg Pathol. 2014;38(5):654-9.

10. Fusco A, Fedele M. Roles of HMGA proteins in cancer. Nat Rev Cancer 2007;7(12):899-910.

11. Reeves R, Nissen MS. The AT-DNA-binding domain of mammalian high mobility group I chromosomal proteins. A novel peptide motif for recognizing DNA structure. J Biol Chem. 1990;265(15):8573-82.

12. Thanos D, Du W, Maniatis T. The high mobility group protein HMG I(Y) is an essential structural component of a virus-inducible enhancer complex. Cold Spring Harb Symp Quant Biol. 1993;58:73-81.

13. Thanos $D$, Maniatis T. The high mobility group protein HMG I(Y) is required for NF-kappa B-dependent virus induction of the human IFNbeta gene. Cell. 1992;71(5):777-89.

14. Miao Y, Cui T, Leng F, Wilson WD. Inhibition of high-mobility-group A2 protein binding to DNA by netropsin: a biosensor-surface plasmon resonance assay. Anal Biochem. 2008;374(1):7-15.

15. Grant MA, Baron RM, Macias AA, Layne MD, Perrella MA, Rigby AC. Netropsin improves survival from endotoxaemia by disrupting HMGA1 binding to the NOS2 promoter. Biochem J. 2009;418(1):103-12.

16. Butler WB. Preparing nuclei from cells in monolayer cultures suitable for counting and for following synchronized cells through the cell cycle. Anal Biochem. 1984;141(1):70-3.

17. Livak KJ, Schmittgen TD. Analysis of relative gene expression data using real-time quantitative PCR and the 2(-Delta Delta C(T)) Method. Methods. 2001;25(4):402-8.

18. Tsuchiya K, Hosoi H, Misawa-Furihata A, Houghton PJ, Sugimoto T. Insulin-like growth factor-l has different effects on myogenin induction and cell cycle progression in human alveolar and embryonal rhabdomyosarcoma cells. Int J Oncol. 2007;31(1):41-7.

19. Kikuchi K, Tsuchiya K, Otabe O, Gotoh T, Tamura S, Katsumi Y, et al. Effects of PAX3-FKHR on malignant phenotypes in alveolar rhabdomyosarcoma. Biochem Biophys Res Commun. 2008;365(3):568-74.

20. Linardic CM. PAX3-FOXO1 fusion gene in rhabdomyosarcoma. Cancer Lett. 2008;270(1):10-8

21. Keller C, Arenkiel BR, Coffin CM, El-Bardeesy N, DePinho RA, Capecchi MR. Alveolar rhabdomyosarcomas in conditional Pax3: Fkhr mice: cooperativity of Ink4a/ARF and Trp53 loss of function. Genes Dev. 2004;18(21):2614-26.

22. Kikuchi K, Rubin BP, Keller C. Developmental origins of fusion-negative rhabdomyosarcomas. Curr Top Dev Biol. 2011;96:33-56.

23. Zhou X, Benson KF, Ashar HR, Chada K. Mutation responsible for the mouse pygmy phenotype in the developmentally regulated factor HMGI-C. Nature. 1995;376(6543):771-4.

24. Rogalla P, Drechsler K, Frey G, Hennig Y, Helmke B, Bonk U, et al. HMGl-C expression patterns in human tissues Implications for the genesis of frequent mesenchymal tumors. Am J Pathol. 1996;149(3):775-9.

25. Rommel B, Rogalla P, Jox A, Kalle CV, Kazmierczak B, Wolf J, et al. HMGl$C$, a member of the high mobility group family of proteins, is expressed in hematopoietic stem cells and in leukemic cells. Leuk Lymphoma. 1997;26(5-6):603-7.

26. Anand A, Chada K. In vivo modulation of Hmgic reduces obesity. Nat Genet. 2000;24(4):377-80.

27. Di Agostino S, Fedele M, Chieffi P, Fusco A, Rossi P, Geremia R, et al. Phosphorylation of high-mobility group protein A2 by Nek2 kinase during the first meiotic division in mouse spermatocytes. Mol Biol Cell. 2004;15(3):1224-32.

28. Chieffi P, Battista S, Barchi M, Di Agostino S, Pierantoni GM, Fedele M, et al. HMGA1 and HMGA2 protein expression in mouse spermatogenesis. Oncogene. 2002;21(22):3644-50.

29. Abe N, Watanabe T, Suzuki Y, Matsumoto N, Masaki T, Mori T, et al. An increased high-mobility group A2 expression level is associated with malignant phenotype in pancreatic exocrine tissue. Br J Cancer. 2003;89(11):2104-9.

30. Meyer B, Loeschke S, Schultze A, Weigel T, Sandkamp M, Goldmann T, et al. HMGA2 overexpression in non-small cell lung cancer. Mol Carcinog. 2007:46(7):503-11.

31. Miyazawa J, Mitoro A, Kawashiri S, Chada KK, Imai K. Expression of mesenchyme-specific gene HMGA2 in squamous cell carcinomas of the oral cavity. Cancer Res. 2004;64(6):2024-9. 
32. Liu Z, Wu K, Yang Z, Wu A. High-mobility group A2 overexpression is an unfavorable prognostic biomarker for nasopharyngeal carcinoma patients. Mol Cell Biochem. 2015;409(1-2):155-62.

33. Schwarm FP, Uhle F, Schanzer A, Acker T, Stein M, Reinges MH, et al. High-mobility group AT-hook protein 2 expression and its prognostic significance in MGMT methylated and unmethylated glioblastoma. Int $J$ Oncol. 2016;48(4):1485-92.

34. Palumbo A Jr, Da Costa NM, Esposito F, De Martino M, D'Angelo $D$, de Sousa VP, et al. HMGA2 overexpression plays a critical role in the progression of esophageal squamous carcinoma. Oncotarget. 2016;7(18):25872-84.

35. Di Cello F, Hillion J, Hristov A, Wood L, Mukherjee M, Schuldenfrei A, et al. HMGA2 participates in transformation in human lung cancer. Mol Cancer Res. 2008;6(5):743-50

36. Kaur H, Hutt-Cabezas M, Weingart MF, Xu J, Kuwahara Y, Erdreich-Epstein A, et al. The chromatin-modifying protein HMGA2 promotes atypical teratoid/rhabdoid cell tumorigenicity. J Neuropathol Exp Neurol. 2015:74(2):177-85.

37. Bridge JA, Liu J, Qualman SJ, Suijkerbuijk R, Wenger G, Zhang J, et al. Genomic gains and losses are similar in genetic and histologic subsets of rhabdomyosarcoma, whereas amplification predominates in embryonal with anaplasia and alveolar subtypes. Genes Chromosomes Cancer. 2002;33(3):310-21.

38. Bouron-Dal Soglio D, Rougemont AL, Absi R, Barrette S, Montpetit A, Fetni $R$, et al. SNP genotyping of a sclerosing rhabdomyosarcoma: reveals highly aneuploid profile and a specific MDM2/HMGA2 amplification. Hum Pathol. 2009:40(9):1347-52

39. Storlazzi CT, Albano F, Locunsolo C, Lonoce A, Funes S, Guastadisegni MC, et al. $\mathrm{t}(3 ; 12)(q 26 ; q 14)$ in polycythemia vera is associated with upregulation of the HMGA2 gene. Leukemia. 2006;20(12):2190-2.

40. Yan J, Zhang Y, Shi W, Ren C, Liu Y, Pan Y. The critical role of HMGA2 in regulation of EMT in epithelial ovarian carcinomas. Tumour Biol. 2016;37(1):823-8

41. Xia YY, Yin L, Jiang N, Guo WJ, Tian H, Jiang XS, et al. Downregulating HMGA2 attenuates epithelial-mesenchymal transition-induced invasion and migration in nasopharyngeal cancer cells. Biochem Biophys Res Commun. 2015;463(3):357-63.

42. Cai J, Shen G, Liu S, Meng Q. Downregulation of HMGA2 inhibits cellular proliferation and invasion, improves cellular apoptosis in prostate cancer. Tumour Biol. 2016;37(1):699-707.

43. Zhao XP, Zhang H, Jiao JY, Tang DX, Wu YL, Pan CB. Overexpression of HMGA2 promotes tongue cancer metastasis through EMT pathway. J Transl Med. 2016;14:26.

44. Shi Z, Wu D, Tang R, Li X, Chen R, Xue S, et al. Silencing of HMGA2 promotes apoptosis and inhibits migration and invasion of prostate cancer cells. J Biosci. 2016;41(2):229-36.

45. Shi Z, Li X, Wu D, Tang R, Chen R, Xue S, et al. Silencing of HMGA2 suppresses cellular proliferation, migration, invasion, and epithelial-mesenchymal transition in bladder cancer. Tumour Biol. 2016;37(6):7515-23.

46. Li M, Cai MY, Lu JB, Hou JH, Wu QL, Luo RZ. Clinicopathological investigation of four cases of desmoplastic small round cell tumor. Oncol Lett. 2012;4(3):423-8.

47. Bizer LS. Rhabdomyosarcoma. Am J Surg. 1980;140(5):687-91.

48. Tapscott SJ, Thayer MJ, Weintraub H. Deficiency in rhabdomyosarcomas of a factor required for MyoD activity and myogenesis. Science. 1993;259(5100):1450-3.

49. Tonin PN, Scrable H, Shimada H, Cavenee WK. Muscle-specific gene expression in rhabdomyosarcomas and stages of human fetal skeletal muscle development. Cancer Res. 1991;51(19):5100-6.

50. Lau KM, Chan QK, Pang JC, Ma FM, Li KK, Yeung WW, et al. Overexpression of HMGA1 deregulates tumor growth via cdc25A and alters migration/ invasion through a cdc25A-independent pathway in medulloblastoma. Acta Neuropathol. 2012;123(4):553-71.

\section{Publisher's Note}

Springer Nature remains neutral with regard to jurisdictional claims in published maps and institutional affiliations.
Ready to submit your research? Choose BMC and benefit from:

- fast, convenient online submission

- thorough peer review by experienced researchers in your field

- rapid publication on acceptance

- support for research data, including large and complex data types

- gold Open Access which fosters wider collaboration and increased citations

- maximum visibility for your research: over $100 \mathrm{M}$ website views per year

At $\mathrm{BMC}$, research is always in progress.

Learn more biomedcentral.com/submissions 